\title{
Học viện Chính trị quốc gia Hồ Chí Minh cần đổi mới tư duy phương pháp luận
}

$04: 34 \mathrm{CH}, 08 / 01 / 2021$

(Chinhphu.vn) - Đồng chí Phạm Minh Chính nhấn mạnh, bối cảnh, tình hình mới đòi hỏi nhiệm vụ của Học viện thời gian tới sẽ nặng nề hơn, trong đó tập trung đổi mới về tư duy phương pháp luận, về bộ máy hoạt động và nguồn nhân lực của toàn bộ hệ thống Học viện.

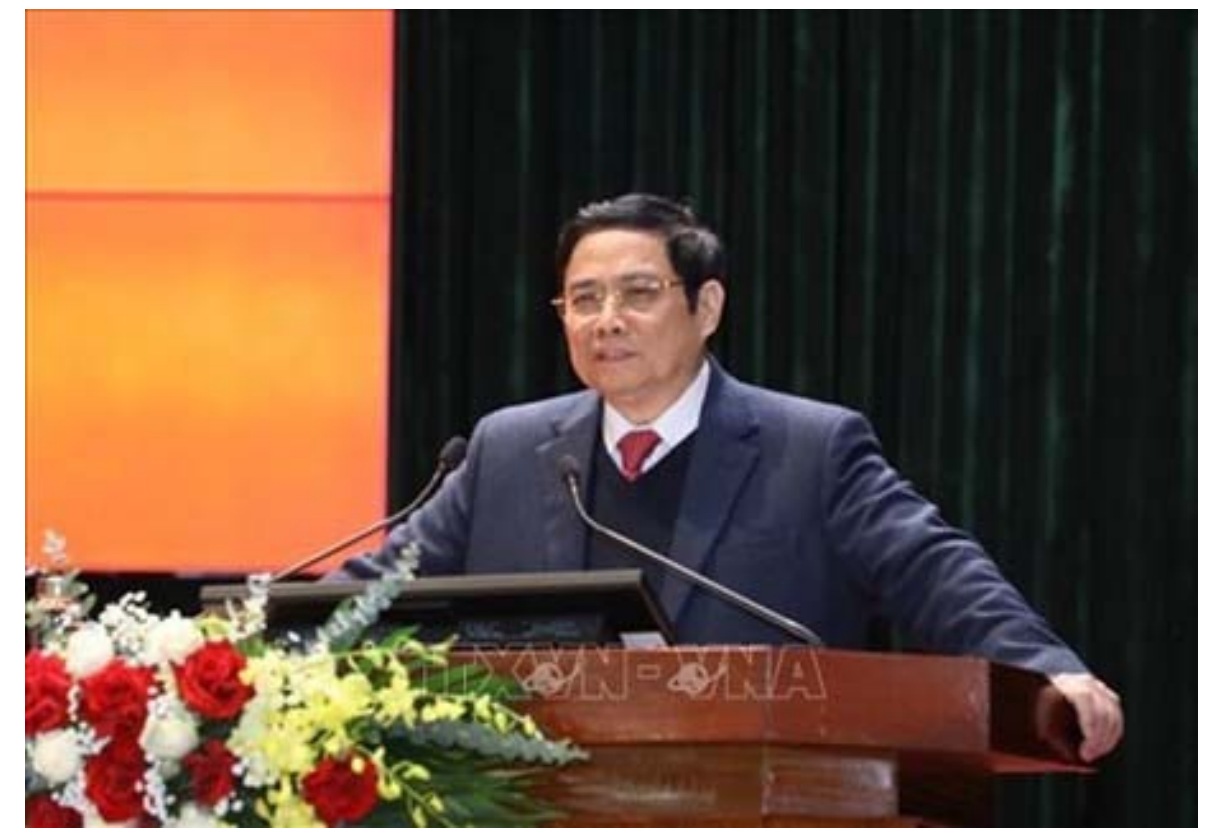

Trưởng Ban Tổ chức Trung ương Phạm Minh Chính phát biểu tại Hội nghị - Ảnh: TTXVN

Sáng 8/1, tại Hà Nội, Học viện Chính trị quốc gia Hồ Chí Minh tổ chức Hội nghị tổng kết công tác năm 2020 và triển khai nhiệm vụ năm 2021 theo hình thức trực tiếp kết hợp trực tuyến với 5 điểm cầu tại các trường chính trị khu vực. Tại điểm cầu Học viện Chính trị quốc gia Hồ Chí Minh, Ủy viên Bộ Chính trị, Bí thư Trung ương Đảng, Trưởng Ban Tổ chức Trung ương Phạm Minh Chính dự, phát biểu chỉ đạo.

Báo cáo tại Hội nghị, Bí thư Trung ương Đảng, Giám đốc Học viện Chính trị quốc gia Hồ Chí Minh, Nguyễn Xuân Thắng cho biết: Trong bối cảnh đại dịch COVID-19 tác động nghiêm trọng, sâu rộng đến tình hình kinh tế-xã hội ở mỗi quốc gia, khu vực, toàn cầu; kinh tế thế giới suy thoái, cạnh tranh chiến lược giữa các nước lớn cùng nhiều biến động phức tạp khác, Đảng ủy, Ban Giám đốc Học viện đã tập trung chỉ đạo các đơn vị trực thuộc thực hiện thành công nhiệm vụ "kép", vừa chống dịch COVID-19 hiệu quả, vừa thực hiện tốt các nhiệm vụ chính trị, chuyên môn của năm 2020.

Theo đó, năm qua, Học viện tiếp tục tăng cường quản lý hệ thống một cách toàn diện trên tất cả các mặt công tác với phương châm: Thực hiện chỉ đạo tập trung, thống nhất nhưng tăng cường phân cấp để các Học viện trực thuộc và viện chuyên ngành phát huy tính chủ động, sáng tạo trong việc thực hiện chức năng, nhiệm vụ được giao. Cùng với đó, quy mô đào tạo, bồi dưỡng của Học viện được điều chỉnh theo hướng đa dạng hóa các loại hình đào tạo phù hợp với yêu cầu nhiệm vụ chính trị và thực tiễn đặt ra. 
Đặc biệt, trong năm 2020, Học viện thực hiện chủ trương tăng tỷ lệ đào tạo tập trung, giảm đào tạo không tập trung. Toàn hệ thống Học viện tổ chức 79 lớp cao cấp lý luận chính trị hệ tập trung với hơn 3.500 nghìn học viên, tăng 26,3\% so với năm 2019.

Cùng với việc tăng quy mô đào tạo tập trung, Học viện đã phối hợp với Tỉnh ủy Quảng Ninh thực hiện thí điểm một lớp Cao cấp chính trị tập trung đặt tại Trường Đào tạo cán bộ Nguyễn Văn Cừ, tỉnh Quảng Ninh.

Đối với nhiệm vụ nâng cao chất lượng công tác nghiên cứu, tổng kết thực tiễn, phát triển lý luận và kiến nghị chính sách; bảo vệ nền tảng tư tưởng của Đảng, đấu tranh phản bác các quan điểm sai trái, thù địch, năm 2020, Học viện đã tổ chức triển khai đồng bộ trên 600 nhiệm vụ khoa học và đạt được nhiều kết quả tích cực. Đặc biệt, Học viện đã chủ động nghiên cứu và chắt lọc kết quả nghiên cứu xây dựng được các báo cáo khuyến nghị về chủ trương, chính sách của Đảng, Nhà nước và đóng góp trong việc soạn thảo Văn kiện Đại hội đại biểu toàn quốc lần thứ XIII của Đảng, được ghi nhận, đánh giá cao, góp phần cung cấp những luận cứ khoa học cho Đảng và Nhà nước trong việc bảo vệ nền tảng tư tưởng của Đảng, hoạch định chủ trương, đường lối, chính sách kịp thời, sát hợp với tình hình diễn biến của thực tiễn đất nước.

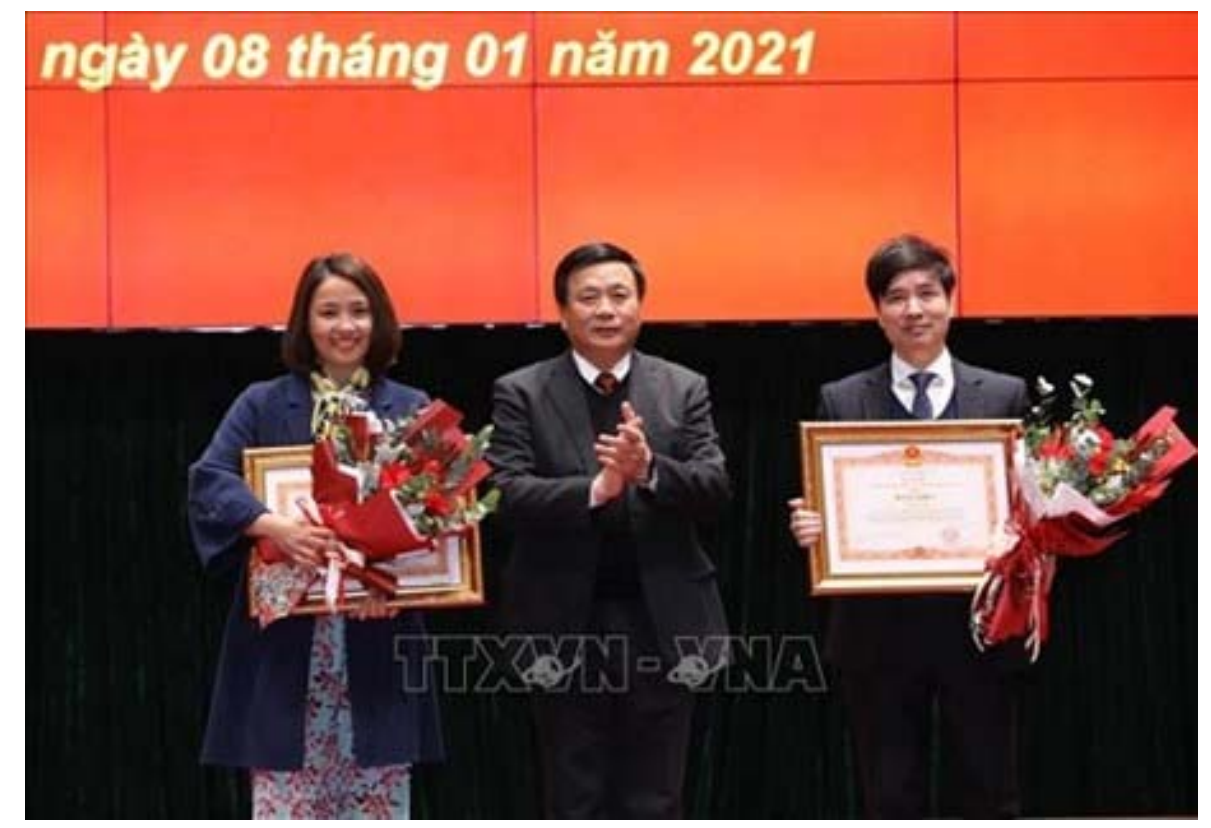

Đồng chí Nguyễn Xuân Thắng, Bí thư Trung ương Đảng, Giám đốc Học viện Chính trị quốc gia Hồ Chí Minh, Chủ tịch Hội đồng Lý luận Trung ương trao Bằng khen của Thủ tướng tặng cho tập thể và cá nhân - Ảnh: TTXVN

Phát biểu chỉ đạo tại Hội nghị, thay mặt Bộ Chính trị, Ban Bí thư, Trưởng Ban Tổ chức Trung ương Phạm Minh Chính biểu dương những kết quả đạt được của Học viện Chính trị quốc gia Hồ Chí Minh trong năm qua. Trong năm 2020, dù gặp nhiều khó khăn, thử thách, Học viện tiếp tục khẳng định vị thế là ngôi trường Đảng cao cấp của Trung ương, hoàn thành tốt nhiệm vụ được giao. Đây là những nỗ lực của tập thể cán bộ, giáo viên, công chức, viên chức, các học viên của Học viện, được kết tinh sau hơn 70 năm xây dựng, trưởng thành và phát triển.

Đồng chí Phạm Minh Chính đề nghị, trong năm 2021 và những năm tiếp theo, Học viện cần tiếp tục quán triệt và triển khai có hiệu quả Nghị quyết Đại hội đại biểu toàn quốc lần thứ XIII của Đảng; Nghị quyết Đại hội Đảng bộ Học viện Chính trị quốc gia Hồ Chí Minh nhiệm kỳ 2020-2025 trên tất cả các mặt công tác. Việc triển khai cần thực chất, đồng bộ và toàn diện trên tất cả các mặt công tác. 
Đồng chí Phạm Minh Chính nhấn mạnh, bối cảnh, tình hình mới đòi hỏi nhiệm vụ của Học viện thời gian tới sẽ nặng nề hơn, trong đó tập trung đổi mới về tư duy phương pháp luận, về bộ máy hoạt động và nguồn nhân lực của toàn bộ hệ thống Học viện.

Trong công tác đào tạo, bồi dưỡng cán bộ, đặc biệt là lực lượng cán bộ nguồn chiến lược, Học viện cần lồng ghép các nội dung trọng tâm của 15 văn bản Trung ương đang có hiệu lực, trong đó có 6 nghị quyết về phát triển kinh tế-xã hội và an ninh quốc phòng, 4 nghị quyết về xây dựng Đảng, 4 nghị quyết về an sinh xã hội và một quy định về nêu gương. Đồng thời, Học viện Chính trị quốc gia Hồ Chí Minh cần tiếp tục bám sát phương châm lấy học viên và giảng viên là trung tâm.

Đồng chí Phạm Minh Chính cũng đề nghị, thời gian tới, Học viện Chính trị quốc gia Hồ Chí Minh cần chú trọng hơn nữa công tác quản lý khoa học theo hướng nâng cao chất lượng nghiên cứu khoa học, đấu tranh phản bác có hiệu quả các quan điểm sai trái, thù địch trong tình hình mới. Cùng với đó, tăng cường ứng dụng công nghệ thông tin vào các bài giảng, vào công tác quản lý lớp, quản lý học viên...

Trưởng Ban Tổ chức Trung ương Phạm Minh Chính tin tưởng, Học viện Chính trị quốc gia Hồ Chí Minh sẽ hoàn thành tốt nhiệm vụ được Đảng, Nhà nước, nhân dân giao phó, xứng đáng là ngôi trường Đảng mang tên Bác Hồ kính yêu.

Nhân dịp này, một số tập thể và cá nhân của Học viện Chính trị quốc gia Hồ Chí Minh đã vinh dự được trao tặng Bằng khen của Thủ tướng Chính phủ, Cờ thi đua của Học viện Chính trị quốc gia Hồ Chí Minh.

theo TTXVN

Bùi Anh Tho'

http://baochinhphu.vn/Thoi-su/Hoc-vien-Chinh-tri-quoc-gia-Ho-Chi-Minhcan-doi-moi-tu-duy-phuong-phap-luan/419264.vgp 


\section{Tài liệu tham khảo:}

[1] Phạm Minh Chính. (2010). Quan hệ công chúng (PR) trong hoạt động kinh tế, khoa học công nghệ và môi trường. Nxb Chính trị Quốc gia, Hà Nội.

[2] Phạm Minh Chính, Vương Quân Hoàng. (2009). Kinh tế Việt Nam: Thăng trầm và đột phá. Nxb Chính trị Quốc gia, Hà Nội.

[3] Phạm Minh Chính, Vương Quân Hoàng. (2008). Bối cảnh tài chính Việt Nam 1997-1998 và 2007-2008: Khoảng cách và biến đối. Nghiên cứu Kinh tế, 48(7), 3-24. 